\title{
Representações Sociais do Rejuvenescimento na Mídia Impressa
}

\author{
Amanda Castro ${ }^{1}$ \\ Adriana de Aguiar \\ Programa de Pós-Graduação em Psicologia da Universidade Federal de Santa Catarina, \\ Florianópolis, SC, Brasil \\ Bruna Berri \\ Universidade Federal de Santa Catarina, Florianópolis, SC, Brasil \\ Brigido Vizeu Camargo \\ Departamento de Psicologia da Universidade Federal de Santa Catarina, \\ Florianópolis, SC, Brasil
}

\section{Resumo}

O objetivo deste estudo foi investigar as representações sociais do rejuvenescimento destacadas a partir de reportagens de capa, publicadas em uma revista de grande circulação nacional. Para este estudo foram selecionadas reportagens da revista Veja, digitalizadas e disponibilizadas no acervo virtual, no site da Editora Abril. Foram analisadas 18 edições em que os termos "rejuvenescer" e "rejuvenescimento" são citados em reportagens de capa. Para a análise dos dados foi utilizada a técnica de análise lexical de conjuntos de segmentos de texto, na qual os comentários foram submetidos a uma Classificação Hierárquica Descendente (CHD), realizada pelo programa informático IRAMUTEQ. Os resultados evidenciados pela CHD denotam que ao longo das décadas as representações sociais do rejuvenescimento foram difundidas contemplando o rejuvenescimento funcional associado à saúde e a longevidade; o rejuvenescimento social atrelado a mudanças no estilo de vida e maior liberdade para o exercício de diferentes papéis sociais e o rejuvenescimento estético, ligado à normatização do corpo em prol da busca pela beleza física. Conclui-se que a voz da autoridade midiática afeta diretamente as representações sociais dos indivíduos, modelando formas de pensar e agir em relação ao envelhecimento, o que contribui para a normatização dos modos de viver, de ser e de lidar com as mudanças que ocorrem no corpo com o passar do tempo.

Palavras-chave: Rejuvenescimento, envelhecimento, mídia impressa, representações sociais.

\section{Social Representations of Rejuvenation in Press Media}

\begin{abstract}
The aim of this study was to research social representations of rejuvenation that stand out on cover reports, published on a magazine with a nationwide circulation. Digitalized articles and reports were selected for this study from Veja magazine, available on the virtual archive at the site of Editora Abril. Eighteen editions were analyzed in which the terms "rejuvenate" and "rejuvenation" were cited on cover articles. So as to analyze the data, a technique of lexical analysis of text segment groups was
\end{abstract}

Endereço para correspondência: Servidão Pedro Manoel da Silveira, 280B, Tapera, Florianópolis, SC, Brasil 88948-520. Fone: (048) 8809-1109. E-mail: amandacastrops@gmail.com, adrianadeaguiar@yahoo.com.br, brunaberri@hotmail.com e brigido.camargo@yahoo.com.br 
used, in which the commentaries were submitted to a Descendent Hierarchical Classification (DHC), processed by the Iramuteq software. The results obtained by the DHC show that through the decades rejuvenation social representations have spread considering functional rejuvenation associated with health and longevity; social rejuvenation linked to lifestyle transformations and an increased freedom to perform different social roles and aesthetic rejuvenation, related with body normalization, on the seek for physical beauty. It concludes the media authority's voice directly affects the social representations of individuals, modeling ways of thinking and acting in relation to aging, which contributes to the standardization of ways of living, being and to deal with the changes that occur in the body over time.

Keywords: Rejuvenation, aging, press media, social representations.

\section{Representaciones Sociales de Rejuvenecimiento en Medios de Prensa}

\section{Resumen}

El objetivo de este estudio consistió en investigar las representaciones sociales del rejuvenecimiento destacadas a partir de reportajes de portada, publicadas en una revista de gran circulación nacional. Para este estudio se seleccionaron reportajes de la revista Veja, digitalizadas y puestas a disposición en el archivo virtual, en el site de la Editora Abril. Se analizaron 18 ediciones en las que los términos "rejuvenecer" y "rejuvenecimiento" son citados en reportajes de portada. Para el análisis de los datos se utilizó la técnica de análisis lexical de conjuntos de segmentos de texto, en la cual los comentarios fueron sometidos a una Clasificación Jerárquica Descendente (CJD), realizada por el programa informático Iramuteq. Los resultados evidenciados por la CJD evidencian que a lo largo de las décadas las representaciones sociales del rejuvenecimiento se difundieron en base al rejuvenecimiento funcional asociado a la salud y a la longevidad; el rejuvenecimiento social ligado a cambios en el estilo de vida y mayor libertad para el ejercicio de diferentes roles sociales y el rejuvenecimiento estético, relacionado a la normalización del cuerpo en favor de la búsqueda de la belleza física. Se concluye que la voz de la autoridad de los medios de comunicación afecta directamente las representaciones sociales de los individuos, modelado formas de pensar y actuar en relación con el envejecimiento, lo que contribuye a la normalización de las formas de vivir, de ser y de hacer frente a los cambios que se producen con el cuerpo con el tiempo.

Palabras clave: Rejuvenecimiento, envejecimiento, medios impresos, representaciones sociales.

Diferentemente dos animais, em que o ciclo de vida é determinado pelo nascimento, maturação, procriação e morte, o ser humano luta pela capacidade de envelhecer, de possuir uma vida cada vez mais longeva (Santos, 2002). Apesar da impossibilidade de deter a chegada da velhice, o homem sempre esteve disposto a retardar o processo de envelhecimento.

As lendas da Grécia Antiga relatam a juventude como atributo dos deuses, por meio de histórias que fazem lembrar a fonte da juventude. Na Idade Média, buscava-se ampliar a longevidade da civilização ocidental por meio de experiências em alquimia, enquanto que no Oriente, nesse mesmo período, havia a crença de que um homem recobraria a juventude mantendo rela- ção sexual com mulheres mais novas (Santos \& Damico, 2009). No século XXI, a tentativa de manutenção da jovialidade ganha nova ênfase a partir das técnicas de rejuvenescimento.

$\mathrm{O}$ rejuvenescimento pode ser definido como o resultado do uso de um conjunto de métodos cirúrgicos, clínicos ou naturais, que visam reduzir os sinais do envelhecimento, para a obtenção de uma aparência mais jovial (Zani, 1994). Atualmente, existe uma ampla gama de tratamentos para melhorar os sinais da idade, desde procedimentos invasivos (cirurgias plásticas), minimamente invasivos (toxina botulínica, ácidos, peelings, lasers, etc.; Sociedade Brasileira de Cirurgia Plástica, 2014), até os chamados "cosmecêuticos", que são produtos que combinam 
características cosméticas e farmacêuticas, sob a promessa de terem sua efetividade cientificamente comprovada (Preetha \& Karthika, 2009; Ribeiro, 2010; Smirnova, 2012). Avanços no campo da medicina antienvelhecimento ainda incluem terapias que transcendem a busca pela restauração da jovialidade física estética, incluindo a manutenção ou até mesmo a reversão de aspectos relacionados à funcionalidade do corpo, como o aumento da energia e da vitalidade. Dentre essas tecnologias, incluem-se terapias como a restrição calórica, uso de antioxidantes, terapias hormonais e intervenções aos níveis genético e molecular, como por exemplo, o uso de células-tronco (Rizvi \& Jha, 2010; Terra \& Boschin, 2004).

Apesar das definições científicas considerarem o rejuvenescimento atrelado a aspectos físicos do corpo, algumas pesquisas na área da psicologia social mostram que este conceito apresenta, no imaginário social, um significado amplo e diversificado que transcende a mera relação com o aspecto físico. Torres (2010), em um estudo com diferentes grupos etários, relatou duas facetas relacionadas ao rejuvenescimento: a subjetiva, que envolve a convivência com outras pessoas, o bem-estar, a espiritualidade e o "sentir-se jovem"; e a funcional, voltada às práticas que visam o retardo do processo de envelhecimento. Teixeira et al. (2007) encontraram resultados semelhantes ao identificaram que o rejuvenescimento é representado como algo positivo, ligado a aspectos estéticos, de saúde e a emoções.

Diante das perdas oriundas do envelhecimento, o rejuvenescimento é avaliado positivamente como um ganho diante das marcas e rugas. Com isso, a forte valorização da capacidade produtiva das pessoas na sociedade moderna torna o rejuvenescimento um objeto de interesse social. O seu estudo em psicologia social demanda que se considerem os conteúdos simbólicos que estão no seu entorno; e para isso a teoria das Representações Sociais (Moscovici, 1976) constitui-se uma abordagem teórica pertinente.

As representações sociais (RS) são teorias leigas utilizadas como grades de interpretação da realidade, que surgem por meio dos processos de comunicação e cooperação entre indivíduos e grupos (Moscovici, 2007). Como um fenômeno resultante da elaboração de explicações sobre questões sociais, as RS têm a comunicação de massa como condição de possibilidade e determinação; por meio da comunicação é possível suscitar debates na esfera pública, trazendo uma determinada temática para o interior das conversas sociais (Jodelet, 2001).

Moscovici (1981) afirma que não é possível estabelecer comunicação sem a partilha de determinadas representações, de forma que uma representação é partilhada e entra na herança social do indivíduo quando ela se torna um objeto de interesse e de comunicação. A mídia, por ser uma importante ferramenta de comunicação em massa, constitui-se como uma importante fonte de informação, o que a torna particularmente relevante para o estudo das RS.

Moscovici (1976) propôs três sistemas de comunicação distintos ao considerar a relação dos atores sociais com a mídia no estudo da RS da psicanálise de parisienses: (a) a propagação, que é um sistema de comunicação que visa expandir e consolidar conteúdos de outras doutrinas ao seu próprio sistema, estabelecido por membros de um grupo que possuem uma visão de mundo organizada em torno de uma crença a propagar; (b) a propaganda, que é um sistema caracterizado por temas que são ordenados sistematicamente e antagonizados, com intenção persuasiva; e (c) a difusão, que consiste em um sistema de comunicação que tem o objetivo de informar e é direcionado a um grupo com identidade difusa, isto é, o receptor da informação não concerne a um grupo social específico, mas sim ao que se chama de massa.

A difusão é o sistema de comunicação típico da imprensa, pois visa a criar um interesse comum sobre determinando assunto (Sá, 1996). A mídia, em especial a impressa, como os jornais e revistas, constituem-se como veículo de difusão de RS (Camargo, 2003; Camargo \& Barbará, 2004). Particularmente em relação ao rejuvenescimento, esse sistema de comunicação contribui para a construção e difusão de padrões sociais relativos a forma como os indivíduos lidam com o corpo que está envelhecendo. 
Como teorias sociais práticas sobre os objetos sociais, as RS se referem a um saber vinculado à experiência que o produziu, servindo ao indivíduo para agir sobre o mundo e sobre o outro (Jodelet, 1989). Essa forma de conhecimento, ao mesmo tempo em que modula simbolicamente o contexto no qual um comportamento ocorre, também envolve uma dimensão de explicação e argumentação, ou seja, quando os indivíduos agem com base em suas teorias leigas, eles simultaneamente elaboram uma explicação que justifique o seu comportamento, como forma de interpretar a realidade e tornar o mundo compreensível (Vala, 2006). Portanto, a difusão midiática de informações acerca do rejuvenescimento contribui para a formação de RS que podem orientar a busca por estratégias que busquem lutar contra o processo de envelhecimento, na medida em que contribuem para o estabelecimento de padrões sociais desejáveis sobre o corpo.

A necessidade de manter um afastamento de uma fase de vida socialmente ligada às perdas físicas e sociais, seja com foco nos aspectos funcionais ou de aparência, fomenta no ser humano o desejo de evitar o envelhecimento (Santos, 2002), o que é enfatizado pela publicidade, que vende a imagem de que as imperfeições do corpo não são normais e muito menos naturais (Debert, 1997). A mídia, por ser uma importante fonte de difusão de RS (Moscovici, 1976), desempenha um papel significativo no processo de valorização da juventude em detrimento da velhice, difundindo informações sobre rejuvenescimento e relacionando-o com bem-estar, atividade, jovialidade e beleza (Couto \& Meyer, 2011; Goetz, Camargo, Bertoldo, \& Justo, 2008; Smirnova, 2012). Ela divulga uma imagem socialmente valorizada e mensagens nas quais a felicidade está atrelada à beleza, juventude, perfeição corporal e sucesso, tornando-os bens ou mercadorias que se pode adquirir (Moreira \& Nogueira, 2008).

Para Goetz et al. (2008), a ênfase em produtos que visam a beleza e a juventude resulta em um fenômeno crescente de culto ao corpo, a partir da utilização em massa de recursos invasivos e não invasivos para rejuvenescer. Considerando o aumento expressivo da busca por estratégias de rejuvenescimento e considerando o papel das
RS na orientação de comportamentos voltados a esse objetivo, o estudo das RS sobre o rejuvenescimento, difundidas na mídia impressa adquire relevância social e científica, na medida em que a exposição cada vez maior aos recursos de transformação do corpo se constitui como uma temática social ligada à saúde.

Enfim, acredita-se que o estudo das RS pode contribuir para uma melhor compreensão de comportamentos ligados à busca de estratégias para o enfrentamento do envelhecimento, a partir de recursos para rejuvenescer, o que pode auxiliar na elaboração de políticas públicas voltadas ao envelhecimento saudável. Considerando-se a importância de se realizar pesquisas que envolvam veículos de difusão de RS, pretende-se identificar e analisar as RS do rejuvenescimento que vem sendo difundidas pela mídia impressa, especificamente em uma revista de circulação nacional.

\section{Método}

O presente estudo teve natureza documental e exploratória. Foram selecionadas reportagens da revista Veja, digitalizadas e disponibilizadas no acervo virtual, no site da Editora Abril e que foram publicadas entre os anos de $1968 \mathrm{e}$ 2013. Conforme dados publicados pela Editora Abril (2013), a revista Veja possui uma tiragem superior a um milhão de cópias, sendo uma das revistas de maior circulação nacional. O critério de escolha da revista deve-se à sua circulação de alcance nacional, considerando que é a revista paga com maior tiragem no país, segundo dados do Instituto Verificador de Circulação, divulgados pela Associação Nacional de Editores de Revista (2013). Foram escolhidas para compor o corpus apenas as reportagens de capa, tendo em vista que tais reportagens apresentam o assunto de principal foco na edição, visando despertar o interesse do leitor.

Foram utilizados os termos "rejuvenescer" e "rejuvenescimento" para a pesquisa das reportagens de capa. Em uma primeira busca, apareceram 57 reportagens com o primeiro termo e 111 reportagens com o segundo. Após a leitura destas reportagens, foram selecionadas 18 , 
considerando-se na seleção o contexto em que os termos "rejuvenescer" e "rejuvenescimento" estavam inseridos. Para isso, foi avaliado se o assunto principal da reportagem referia-se ao rejuvenescimento ou se o termo era mencionado em reportagens que tinham como destaque outros assuntos. As reportagens que se enquadravam neste último caso foram excluídas da análise. Foram selecionadas 2 reportagens de capa da década de 80, 6 reportagens da década de 90 , 7 reportagens da década de 2000 e 3 reportagens da última década, a partir do ano de 2010 até o ano de 2013 (edições disponíveis no acervo virtual).

As reportagens de capa foram organizadas em um arquivo único, compondo o corpus de análise. O conteúdo de cada reportagem foi identificado por uma linha de comando, contendo como variáveis o ano, a década da reportagem e a edição da revista. O corpus foi submetido a uma Classificação Hierárquica Descendente (CHD) com o auxílio do programa informático IRAMUTEQ (Interface de R pour analyses Multidimensionnelles de Textes et de Questionnaires). A CHD consiste em uma modalidade de análise de dados desenvolvida por Reinert (1990) que visa classificar o material textual em segmentos de textos (ST's), baseados em vocabulários específicos. Os segmentos de textos são repartidos com base na frequência de palavras, originando classes que, ao mesmo tempo, apresentam vocabulário semelhante entre si e vocabulário diferente dos ST's das outras classes (Camargo \& Justo, 2013). O IRAMUTEQ possibilita que se recuperem, no corpus original, os segmentos de texto associados a cada classe, momento em que se obtém o contexto das palavras estatisticamente significativas, o que possibilita ao pesquisador realizar uma análise mais qualitativa dos dados. As classes geradas a partir da classificação hierárquica descendente representam o contexto de sentido das palavras e podem apontar RS ou elementos de RS sobre o objeto social estudado (Camargo, 2005).

A seleção das palavras características de cada classe foi realizada manualmente pelos pesquisadores, seguindo os seguintes critérios: (a) palavras cuja frequência no corpus foi superior à frequência média por palavra $(>5)$; (b) associação significativa da palavra com a classe, obtida através de teste de qui-quadrado $\left(\chi^{2}=3,84\right.$, pois o cálculo do texto é feito com base em uma tabela com grau de liberdade igual a 1); (c) $p$-valor $<0,05$.

\section{Resultados}

Para a análise o programa reconheceu a separação do corpus em 18 textos, que foram fracionados em 1.068 ST's, dos quais $77,34 \%$ foram retidas na CHD. O corpus foi dividido em cinco classes categorizadas nominalmente pelos pesquisadores. A análise qualitativa das palavras para a nomeação das classes se deu considerando os segmentos de textos que são o ambiente das palavras e que permitem a contextualização do vocabulário típico de cada classe. Na Figura 1 pode-se visualizar as palavras características de cada classe, segundo sua frequência nas mesmas.

A Figura 1 mostra as relações entre as classes resultantes da CHD. Em um primeiro momento, o programa dividiu o corpus em dois subcorpora, o primeiro originando a classe 1, e o outro as demais classes. Num segundo momento, o segundo subcorpus sofreu outra partição, dividindo-se em outros dois subcorpora, o primeiro originando a classe 2 e o segundo três outras classes (3, 5 e 4). Em um terceiro momento o segundo subcorpus, resultante da segunda partição, dividiu-se em duas partes, uma dando origem a classe 3 e as outras classes: 4 e 5 .

A primeira classe a se diferenciar do restante do corpus (Classe 1), denominada "Práticas Estéticas", representa $23,78 \%$ dos ST's retidos na análise, corresponde a segunda maior classe e apresenta predominantemente reportagens mais recentes, publicadas na década de 2010 . Os conteúdos que compõe esta classe tratam de recursos estéticos que visam à busca da beleza e do rejuvenescimento físico. Fazem referência a intervenções e procedimentos estéticos empregados para a atenuação dos efeitos do envelhecimento no corpo, como preenchimentos de rugas e sulcos com toxina botulínica, colágeno, ácidos e gorduras, e clareamento de manchas através de procedimentos como o laser. 


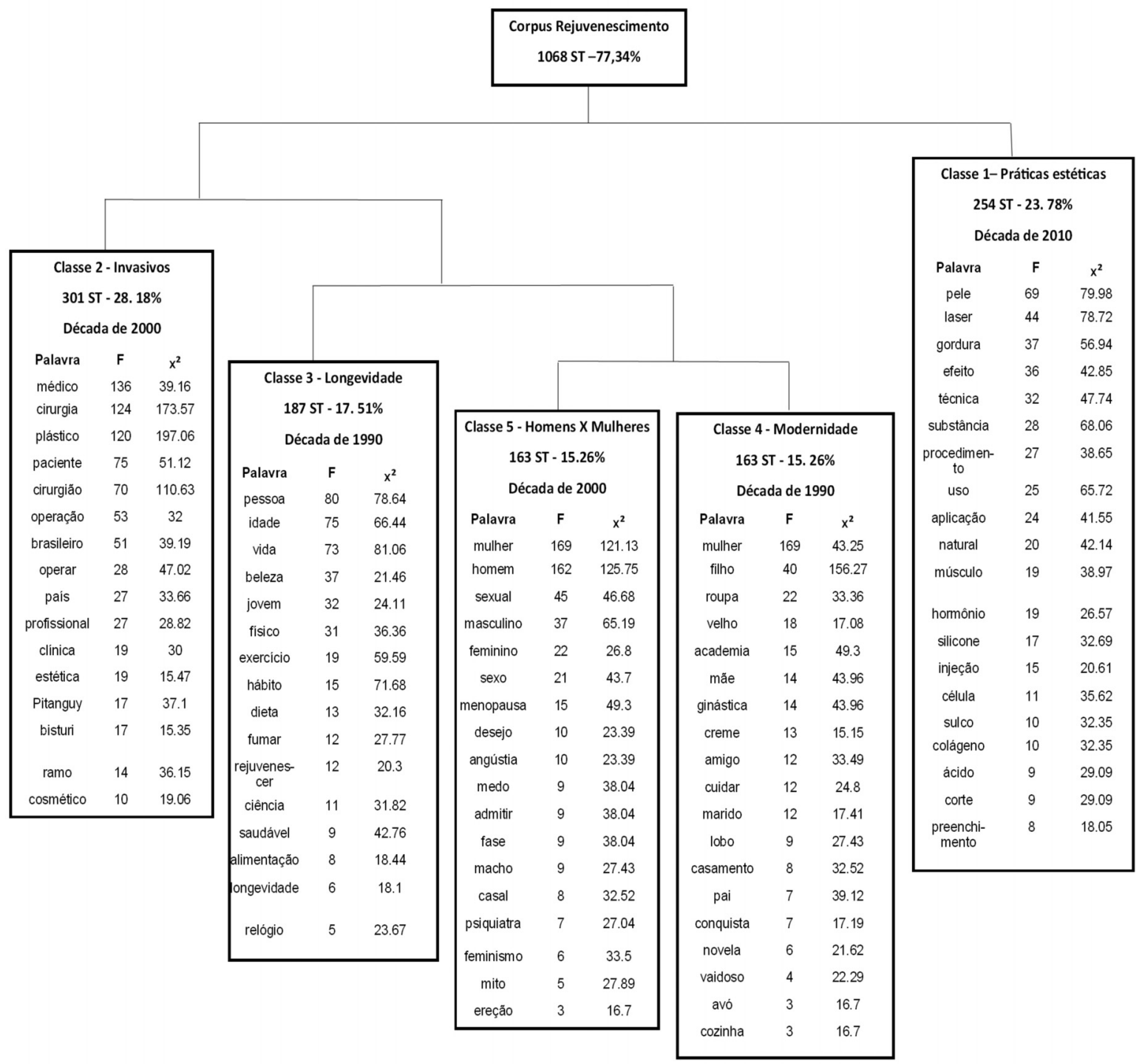

Figura 1. Dendograma de classes sobre as as representações sociais do rejuvenescimento.

As reportagens que fazem parte da classe 1 trazem informações de especialistas e enfatizam o aprimoramento dos procedimentos de rejuvenescimento e retardo do envelhecimento, levantando suas vantagens e desvantagens. $\mathrm{O}$ aprimoramento das técnicas cirúrgicas e o desenvolvimento de procedimentos estéticos pouco invasivos possibilitam menores efeitos colaterais e um resultado estético mais natural. Os trechos a seguir ilustram esse contexto:

Todas as intervenções estéticas à base de laser consistem em danificar parte das células da área tratada de modo a estimular a renovação celular. É nesse processo que manchas, vincos, marcas de expressão e pés de galinha desaparecem - ou são no mínimo bastante atenuados. É possível rejuvenes- cer a pele em até cinco anos mas para isso é necessária uma aplicação por mês durante quatro meses além disso em dois anos é preciso voltar ao consultório do dermatologista. (Edição 2146, ano 2010: Laser: A medicina da luz, pp. 71-72).

Além de fazer um lifting ela experimentou a nova técnica de enxerto de gordura em sulcos localizados e em todo o contorno do maxilar criando um formato facial sutilmente melhorado. $\mathrm{O}$ uso de gordura para alisar rugas e compensar a perda de volume característica do envelhecimento em áreas como as maçãs do rosto e as mãos é festejado por muitos cirurgiões plásticos tanto pelo efeito quanto pela durabilidade. Ao contrário dos enxertos que começaram a ser realizados na 
década de 80 , os procedimentos hoje são feitos com gordura pura rica em células tronco que, em questão de meses, se transformam nos desejados fibroblastos, os produtores de colágeno e elastina, e livres de líquidos responsáveis pela rápida reabsorção. No caso das mãos, há quase unanimidade entre os cirurgiões de que essa gordura boa é a melhor solução para injeções de preenchimento. "Antes havia apenas métodos paliativos, como cremes e aplicações de laser, com resultado mediano, e o ácido hialurônico, cujo efeito desaparecia em poucos meses", diz o médico Volney Pitombo. (Edição 2146, ano 2010; Operação verão, pp. 124-125)

Uma segunda partição diferencia a classe "Invasivos" (Classe 2), que representa 28,18\% do total dos ST's e está associada a reportagens publicadas durante a década de 2000 . A classe 2 corresponde a maior classe e também traz conteúdos relacionados a intervenções estéticas de beleza e rejuvenescimento, no entanto com foco em intervenções invasivas, como a cirurgia plástica. A cirurgia plástica é retratada como um dos ramos mais lucrativos da medicina e em processo de popularização no Brasil, por ser uma intervenção capaz de melhorar rapidamente a aparência, corrigindo traços corporais e marcas do tempo consideradas indesejáveis. É apresentada como um recurso promotor de autoestima, no entanto a busca, quando realizada em excesso, é vista como um indicativo de um possível problema emocional referente à autoimagem corporal. Como pode ser exemplificado no trecho:

Há vítimas de dismorfia que chegam a submeter-se a nove cirurgias de nariz; existem ainda aquelas que praticam uma espécie de turismo médico batizado pelos especialistas de doctor shopping, rodam de consultório em consultório em busca de sugestões sobre o que deveriam mudar em sua imagem (Edição 2067, ano 2008: Quando o belo... Ganha a máscara da plástica, p. 112).

As reportagens que compõe esta classe também trazem a cirurgia plástica como um recurso que, embora historicamente relacionado ao universo feminino, vem ganhando cada vez mais adeptos entre a população masculina, como destacado:

Até pouco tempo atrás a operação plástica para correção estética era coisa de mulher; hoje os homens também estão na fila. Vinte por cento dos clientes de cirurgia plástica são representantes do ainda chamado sexo forte: eles querem aumentar o queixo com silicone, livrar-se da papada, tirar alguns centímetros da barriga ou perder os pneuzinhos da cintura. (Edição 1428, ano 1996; “O macho acorda", p. 70)

As reportagens também trazem informações referentes ao crescimento do número de cirurgiões plásticos no Brasil e da qualidade técnica destes profissionais. É enfatizada a importância de se escolher um profissional conceituado, para que se obtenha o resultado esperado. $\mathrm{O}$ aumento do número de cirurgias plásticas no Brasil é entendido como um resultado do aumento da qualidade do procedimento e da facilitação do acesso à população, o que contribui muitas vezes para a banalização da busca por este recurso, conforme ilustrado:

São na verdade anúncios de clínicas de cirurgia plástica veiculados em revistas especializadas no ramo como Plástico \& Beleza e Corpo \& Plástica essa é uma das faces da popularização das operações estéticas no país para se ter uma ideia só no ano passado trezentos e cinquenta mil brasileiros caíram na faca para ficar mais bonitos ou seja em cada grupo de cem mil habitantes duzentos e sete foram operados. (Edição 1741, ano 2002: Corpos à venda, p. 84)

A classe 3, denominada "Longevidade" aborda o rejuvenescimento menos sob o ponto de vista estético e mais sob a perspectiva da longevidade, estando associada às reportagens veiculadas durante a década de 1990 . O aumento na expectativa de vida é visto como uma consequência do avanço tecnológico alcançado nas últimas décadas. A manutenção de determinados hábitos, como cuidados com a alimentação, prática de exercícios físicos e evitar o fumo, também aparecem como recursos para o aumento da longevidade e maior qualidade de vida. Um estilo de vida saudável, composto por um conjun- 
to de práticas, é considerado como uma forma de atrasar o relógio, de se manter jovem e obter uma vida mais longeva, como pode ser destacado no trecho: "No que diz respeito aos hábitos, os cientistas estão convencidos de que uma dieta pobre em calorias e recheada de exercícios moderados ajuda a asfaltar a avenida que leva à vida mais longa e saudável" (Edição 1140, ano 1990: "Fonte da juventude", p. 59) e ainda:

Muitos médicos temem que o entusiasmo pelas vitaminas contamine os pacientes que, sentindo-se protegidos, passem a negligenciar cuidados óbvios com a saúde, como fazer algum tipo de exercício físico, alimentar-se com uma dose razoável de bom senso e não abusar de álcool ou do fumo. (Edição 1294, ano 1993: "A química da vida", p. 78) Nesta classe, o rejuvenescimento aparece associado à manutenção de um corpo saudável e funcional por mais tempo, o que requer, além da adoção de práticas corporais saudáveis, também o envolvimento em ações que estimulem a atividade da mente e o aprendizado. Como pode ser representado pelo trecho: "A doutora Kawas aconselha as pessoas a se manter sempre dispostas a enfrentar novos desafios intelectuais, exercitar a mente com leituras e conviver num ambiente culturalmente renovador como a grande terapia para preservar o cérebro jovem por muito tempo" (Edição 1140, ano 1990: "Fonte da juventude", p. 61).

A classe "Modernidade" (classe 4) traz conteúdos que vinculam o rejuvenescimento às mudanças observadas no estilo de vida das pessoas ao longo dos anos, principalmente das mulheres, e apresenta majoritariamente reportagens publicadas na década de 1990. A mulher moderna, principalmente a partir dos 40 anos, é retratada como aquela que se preocupa muito mais com a manutenção da aparência e do bem-estar, buscando recursos que promovam mais qualidade de vida, como a prática de exercícios físicos e adoção de comportamentos considerados pela sociedade como joviais. O trecho que segue exemplifica esse contexto:

Enquanto as mães das atuais quarentonas quase não tinham opções fora da reclusão no lar, cuidando de filhos e netos, fazendo tricô e assistindo televisão, as pós balzaquianas de hoje querem mais muito mais na batalha por uma maturidade viçosa e útil, com bem estar, saúde, boa aparência e sexo; lotam os horários matinais das academias de ginástica de shortinho e camiseta muitas vezes tomados emprestados das filhas. (Edição 1399, ano 1995: A batalha começa aos quarenta, p. 84)

Observa-se através das reportagens associadas à classe 4, que a mulher contemporânea, de meia idade, supera papéis tradicionais e passa a exercer com liberdade comportamentos que não se enquadravam culturalmente como característicos de sua faixa etária. A imagem da mulher "loba" é difundida principalmente pelas novelas e suas atrizes. Destaca a imagem de uma mulher segura e independente em relação às suas escolhas e ao exercício de novos papéis:

"As lobas estão mostrando que sua capacidade criadora não está restrita à procriação, que não estão acabadas porque não podem mais gerar filhos". . . ."É cruel demais assumir que a vida termina cedo. As mulheres têm uma capacidade de renovação maravilhosa e têm de usar isso", concorda a atriz Suzana Vieira 52 anos um exemplo acabado de loba, que vai à luta há nove anos. Ela mora com o operador financeiro Carson Gardeazabal, 34 anos, quase a mesma idade de seu filho Rodrigo de 30 . Os dois se conheceram durante as gravações da novela Cambalacho, na época Carson era piloto de motocross e fazia uma ponta na novela. "Ele era um deus grego lindo louro e forte", baba Suzana que não teve dúvidas em trocar o namorado da sua idade pelo garotão . . . À época uma quarentona, Suzana enfrentou preconceitos: "fazer anos no Brasil ainda é apavorante, parece que você é obrigada a mudar, há uma lista de coisas que uma mulher de determinada idade não pode fazer", diz a atriz. "Outro dia li numa reportagem que mulheres com mais de 25 anos não podem usar vestido baby look, eu uso até hoje, adoro roupa justa, curta, minissaia, decotes não estou nem aí, não estou ofendendo ninguém e só paro de usar no dia 
que for presa", completa, ciente da concorrência das mais jovens. (Edição, 1399, ano 1995: A batalha começa aos quarenta, p. 88) A classe 5, traz reportagens publicadas principalmente entre a década de 2000. Intitulada "Homens X Mulheres", ela traz conteúdos ligados às pessoas de meia-idade, no entanto retrata a relação entre os gêneros e as mudanças que são observadas na busca pelo enfrentamento do envelhecimento entre homens e mulheres. A década dos quarenta anos é retratada como uma fase em que a mulher passa por muitas mudanças; há perdas físicas relativas à redução hormonal causada pela menopausa, mas concomitantemente, também pode ser uma fase positiva em que é permitido à mulher aproveitar mais a vida, podendo ser feliz e sexualmente ativa depois de atingida a maturidade. Já os homens passam a enfrentar dificuldades sexuais, em virtude de problemas com ereção, fato gerador de angústia e medo, mas que pode ser combatido por meio de medicamentos ou próteses.

Esta classe também retrata a maior liberdade por parte das mulheres para exercer atividades tradicionalmente associadas ao universo masculino, ao mesmo tempo em que também é socialmente permitido aos homens se preocuparem e cuidarem da aparência, conforme destacado no excerto:

A preocupação dos homens com a forma física, os cabelos e as roupas se tornou um movimento comportamental bem mais definido e complexo; não é somente de aparência que se fala, mas de uma nova maneira de ver o mundo, de atuar nele de uma forma impensável para as gerações passadas. (Edição 1822, ano 2003; "O homem em nova pele", p. 64)

\section{Discussão}

A análise das reportagens publicadas pela revista Veja nas últimas 6 décadas possibilitou identificar informações sobre o rejuvenescimento que foram difundidas pela mídia ao longo do período estudado. Supõe-se aqui que este meio de comunicação, ao popularizar para a massa conhecimentos produzidos pela ciência, pode influenciar o pensamento coletivo em um determinado momento, contribuindo assim para a produção e veiculação das RS(Camargo, 2003; Moscovici, 1981).

No caso do rejuvenescimento, a análise das informações difundidas pela mídia impressa, permite verificar o ambiente de modelagem das informações científicas que são direcionadas às pessoas e que, ao serem apreendidas pelos atores sociais, participam da elaboração de um saber popular que irá orientar as interações sociais e as condutas referentes à relação das pessoas com o próprio corpo. Foram encontradas reportagens focadas nos métodos e práticas de rejuvenescimento, embelezamento, emagrecimento, bem como relativas ao bem estar social e psíquico. As reportagens de capa selecionadas apresentam textos abrangendo o saber técnico de profissionais vinculados à Medicina, Saúde e Estética e textos que apresentam opiniões de figuras públicas.

Os conteúdos difundidos na década de 90 mostram que as primeiras informações relativas ao rejuvenescimento ligavam-no à ideia de longevidade (classe 3); e às transformações no estilo de vida da população, principalmente da mulher, que passa a exercer novos papéis e a ter maior liberdade para dedicar-se ao cuidado com o próprio corpo (classe 4). Os trechos de reportagens destacados na classe "longevidade" difundem informações de especialistas que ressaltam cuidados com a alimentação, prática de exercícios físicos e medidas para deixar de fumar como práticas para manutenção da saúde e aumento da expectativa e qualidade de vida. $\mathrm{O}$ rejuvenescimento aparece como o resultado de um conjunto de estratégicas que buscam atenuar ou mesmo retardar o processo de degeneração física que ocorre com o envelhecimento.

As informações difundidas na mídia que associam o rejuvenescimento à manutenção funcional do corpo e à promoção da saúde refletem-se nas RS do rejuvenescimento que circulam na sociedade, e contribuem para o compartilhamento da crença de que é possível atrasar o relógio biológico e ganhar tempo com qualidade, por meio da manutenção de certos hábitos considerados pelos especialistas como saudáveis. Esse 
dado é corroborado por Torres (2010) na medida em que o rejuvenescimento, no estudo da autora, apareceu vinculado à ideia de longevidade, saúde e vitalidade. A ênfase em aspectos de saúde predominantemente nas reportagens da década de 90 pode ter sido em decorrência do crescimento considerável nas importações de alimentos industrializados no Brasil nesta década, decorrente da abertura de mercado, o que possivelmente influenciou no aumento da preocupação do brasileiro com a alimentação e prática de atividades físicas (Diez-Garcia, 2003).

As mudanças relativas ao estilo de vida da população e sua relação com o corpo são destacadas em algumas reportagens publicadas na década de 1990, pertencentes à classe Modernidade (classe 4). Nesse contexto, a mulher moderna passa a ocupar espaço relevante no mercado de trabalho, obtendo ascensão profissional, principalmente a partir dos 40 anos e, nessa etapa, passa a preocupar-se muito mais com a manutenção da aparência jovial e do bem-estar (Biasoli-Alves, 2000). O rejuvenescimento feminino é representado como a superação de papéis tradicionais, considerados retrógrados por vincularem a idade cronológica ao exercício de determinados papéis sociais, como mãe, esposa, avó. A relação entre novos papéis sociais da mulher e práticas de rejuvenescimento é igualmente analisada a partir do estudo de campanhas publicitárias, realizada por Palacios (2006). Este autor destaca que, a partir de 1990, os anúncios publicitários de cosméticos passam a dividir produtos por faixas etárias e aconselham cuidados com a saúde desde cedo para preservar a beleza na idade madura, ocorrendo o mesmo com a divulgação de atividades físicas voltadas às mulheres.

A valorização da aparência jovial difundida pela mídia é também destacada no estudo de Haboush, Warren e Benuto (2011), em que a boa aparência é associada à saúde, estando vinculada à atividade e funcionalidades para manter-se ativo. Do mesmo modo, Hubert e De Labarre (2005) afirmam que as discussões sobre o corpo abrangem predominantemente aspectos da saúde, da forma e da alimentação. Assim, a manu- tenção de funcionalidades parece relevante para o estilo de vida destacado nos anos 90, e nesse contexto, a relação com o corpo parece associada à saúde e atividade.

A classe Homens X Mulheres (classe 5), apresenta a relação entre os gêneros no que se refere ao enfrentamento dos sinais do envelhecimento para homens e mulheres. Aqui o foco recai sobre as mudanças funcionais no corpo por conta das alterações hormonais e as implicações destas nas relações sociais. A menopausa, retratada como um marcador na vida funcional das mulheres, e a impotência sexual são vistas como perdas acarretadas pelo envelhecimento, que possuem implicação no exercício da sexualidade. Embora o foco das reportagens esteja sobre a mulher, como também identificado por Smirnova (2012), os trechos de reportagem trazem as primeiras indicações a respeito de mudanças em aspectos normativos na relação entre cuidados com o corpo e gênero, de forma que os homens começam a adotar práticas de embelezamento e rejuvenescimento e as mulheres passam a voltar-se à carreira e sua identidade profissional. Em 2000 há o declínio dos papéis sociais cristalizados em função do gênero, surgem novas tendências sociais em relação às práticas de cuidados corporais (Freitas, 2011).

A mudança na conjectura econômica e social alavancou a popularização de práticas interventivas voltadas às alterações no corpo. Em 2001, aos 40 anos, a mulher é apresentada nos trechos de reportagem no auge das possibilidades profissionais, acadêmicas e sexuais, de modo que quaisquer disfunções orgânicas ou sinais de envelhecimento são apontados como passíveis de tratamento. A norma social e principalmente a cultura ocidental, apresentam a mulher mais velha como uma vítima de velhice. A mulher é considerada como parte da população "em risco" que deve monitorar, tratar e prevenir quaisquer marcadores de velhice. Para a mulher, a representação do processo de envelhecimento pode apresentar mais elementos relativos a perdas do que ganhos, na medida em que seus atributos físicos são fatores relevantes nas competições afetivas e profissionais. Esse 
envelhecimento pode trazer sentimentos de baixa autoestima e alguns desequilíbrios psicológicos, incentivando uma busca pelo rejuvenescimento (Teixeira et al., 2007).

A partir da década de 2000, como pode ser observado na classe 2 , as reportagens publicadas enfatizam o rejuvenescimento atrelado à intervenções estéticas e à valorização da aparência física, destacando-se as transformações artificiais no corpo por meio da cirurgia plástica. No ano 2000 o Brasil apresentou destaque no cenário internacional, em relação à procura por este procedimento. A ampla divulgação dos procedimentos, por meio de figuras públicas, como atrizes, que assumiam ter feito cirurgias plásticas com Ivo Pitanguy, renomado cirurgião plástico da década, são destaques nos trechos de reportagens que tinham por objetivo destacar que "rejuvenescer é necessário para a autoestima". Em seus estudos Kellner (2001) afirma que a mídia apresenta e destaca imagens e figuras com as quais o público possa identificar-se e, logo, imitar. A voz de autoridade midiática pode afetar diretamente as RS dos indivíduos. Assim sendo, a mídia utiliza de figuras públicas, na condição de modelos a fim de valorizar formas de comportamento e modos de ser. Um aspecto positivo relacionado à procura por juventude corporal reside no autocuidado e no aumento da autoestima, por outro lado, como destacado por Goetz (2013), há um risco do exagero no consumo desses produtos associados às figuras públicas, que pode conduzir à psicopatologia.

A imagem do corpo modificado pela cirurgia plástica ganha status de normalidade, na medida em que o procedimento cirúrgico rejuvenescedor é largamente difundido pelos meios de comunicação (Bordo, 1993), refletindo-se nas representações elaboradas. A cirurgia plástica apareceu no estudo de Teixeira et al. (2007) como um elemento presente na RS do rejuvenescimento, enquanto que no estudo de Camargo, Justo e Jodelet (2010) se mostrou como um recurso utilizado principalmente entre as mulheres para a obtenção da beleza física e a satisfação corporal.

A Classe denominada "Práticas Estéticas" (classe 1), associa-se às reportagens mais recen- tes, publicadas na década de 2010 e apresentam informações referentes às novas intervenções estéticas de rejuvenescimento, que surgem em virtude do desenvolvimento tecnológico e da necessidade de se investir em intervenções e procedimentos que ofereçam menos riscos a saúde e um efeito estético melhor. Difunde-se, através da mídia, a ideia de que é possível e desejável embelezar e remodelar o corpo; viver mais e com mais qualidade, ao mesmo tempo em que é possível envelhecer mantendo uma aparência jovem e bela. Em relação à primazia da beleza, Camargo, Goetz, Barbará e Justo (2007), ao estudarem a RS deste objeto, identificaram que a beleza corporal foi associada à juventude e ao corpo remodelado e apareceu vinculada aos padrões estéticos e à produção cultural de embelezamento do corpo. As marcas que deixam claro a impossibilidade de deter o curso do envelhecimento são incômodas e geralmente são evitadas e tratadas, pois culturalmente o corpo é um capital, conforme destacam Bourdieu (2001) e Goldenberg (2008). Apesar dos ideais de beleza corporal feminina sofrerem modificações ao longo do tempo, um dado que permanece imutável é que as mulheres mais do que os homens são incentivadas a mudar sua forma corporal em conformidade com o conceito de imagem ideal (Camargo, Goetz, \& Barbará, 2005). Camargo et al. (2010) identificaram uma maior insatisfação das mulheres com o corpo em comparação com os homens, bem como maior adesão em práticas de controle do corpo. Os autores concluem que há uma maior submissão às normas sociais referentes ao corpo por parte das mulheres.

Os conteúdos principalmente das classes 1 e 2, fazem alusão de que é fácil, rápido e cada vez mais seguro e barato ficar belo e mais jovem com as técnicas disponíveis. A diversidade e popularidade dos recursos rejuvenescendores reforça a ideia de que as pessoas, principalmente as mulheres, tem o dever de se manterem jovens, independente da idade. A mídia, ao impor um padrão social, exerce um poder disciplinador e normativo sobre o corpo. Nesse contexto, frente a tantos recursos de rejuvenescimento e beleza, as mulheres acabam sendo responsabilizadas 
pela visibilidade do próprio envelhecimento, uma forma de negligência consigo própria.

A mídia, então, difunde RS que são utilizadas como meio para persuadir e associar a aparência jovem como essencial e fundamental para a realização pessoal, a felicidade e a valorização social. A construção da mulher ideal é aquela que, além de manter um corpo jovem e belo, também é bem sucedida profissionalmente e mostra segurança pessoal. Assim, ela estabelece, por meio da imagem de figuras públicas e do discurso de especialistas na área, a normatização dos modos de viver e de ser, da forma como as pessoas lidam com o próprio corpo e com o processo de envelhecimento.

\section{Considerações Finais}

O presente estudo buscou investigar as RS do rejuvenescimento na mídia impressa, especificamente nas reportagens de capa de uma revista de circulação nacional. Ao longo das décadas, identificou-se que as RS do rejuvenescimento foram difundidas contemplando três aspectos: (a) $\mathrm{O}$ rejuvenescimento funcional associado à saúde e a longevidade; (b) O rejuvenescimento social atrelado a mudanças no estilo de vida e maior liberdade para o exercício de diferentes papéis sociais, e (c) O rejuvenescimento estético, ligado à normatização do corpo em prol da busca pela beleza física.

A análise das informações veiculadas pela mídia impressa permitiu explorar um campo em que o conhecimento científico é difundido e popularizado, tornando-se vetor para a produção das RS (Camargo, 2003). Os meios de comunicação, ao divulgarem informações científicas sobre o rejuvenescimento, são fundamentais na determinação de suas representações e, como essa forma de conhecimento tem um papel importante na dinâmica das relações e práticas sociais, as RS vinculadas pela mídia modelam as práticas relativas a este objeto, criando modelos de beleza que são absorvidos pela sociedade, impondo um padrão a ser copiado e desejado.

Este estudo, ao analisar as RS do rejuvenescimento na mídia impressa, contribui para o avanço do conhecimento na área, uma vez que este objeto, apesar de apresentar grande relevância social em um país com acelerado processo de envelhecimento populacional, como o Brasil, ainda é pouco explorado pela psicologia. Em contrapartida, a abordagem apenas das reportagens de capa de uma única revista se mostrou uma limitação ao estudo, de forma que os resultados devam ser interpretados de forma parcial. Sugerem-se outras pesquisas que contemplem maior variedade de fontes de informação impressa e outras modalidades de mídias populares como meio de abranger a diversidade e quantidade de assuntos sobre a temática.

\section{Referências}

Associação Nacional de Editores de Revista. (2013). Maiores circulações: Revistas semanais. Recuperado em http://aner.org.br/dados-de-mercado/ circulacao/

Bordo, S. (1993). Feminism, Foucault and the politics of the body. In C. Ramazanoglu (Ed.), $U p$ against Foucault: Explorations of some tensions between Foucault and feminism (pp. 179-202). London: Routledge

Biasoli-Alves, Z. M. M. (2000). Continuidades e rupturas no papel da mulher brasileira no século XX. Psicologia: Teoria e Pesquisa, 16(3), 233239. doi:10.1590/S0102-37722000000300006

Bourdieu, P. (2001). O poder simbólico. Petrópolis, RJ: Vozes.

Camargo, B. V. (2003). A televisão como vetor de difusão de informações sobre a AIDS. In M. L. P. Coutinho, A. S. Lima, M. L. Fortunato, \& F. B. Oliveira (Eds.), Representações sociais: Abordagem interdisciplinar (pp. 130-152). João Pessoa, PB: Editora da Universidade Federal da Paraíba.

Camargo, B. V. (2005). Alceste: Um programa informático de análise quantitativa de dados textuais. In A. S. P. Moreira, J. C. Jesuino, \& B. V. Camargo (Eds.), Perspectivas teórico-metodológicas em representações sociais (pp. 511-539). João Pessoa, PB: Editora da Universidade Federal da Paraíba.

Camargo, B. V., \& Barbará, A. (2004). A difusão científica da AIDS na mídia impressa. Psico, $35(2), 160-176$. 
Camargo, B. V., Goetz, E. R., \& Barbará, A. (2005, ago.). Representação social da beleza de estudantes de moda. Trabalho apresentado na IV Jornada Internacional e II Conferência Brasileira sobre Representações Sociais, João Pessoa, PB, Brasil.

Camargo, B. V., Goetz, E. R., Barbará, A., \& Justo, A. M. (2007, ago.). Representação social da beleza de estudantes de educação física e de moda [Resumo]. Trabalho apresentado na V Jornada Internacional e III Conferência Brasileira sobre Representações Sociais, Brasília, DF, Brasil.

Camargo, B. V., \& Justo, A. M. (2013). Iramuteq: Um software gratuito para análise de dados textuais. Temas em Psicologia, 21(2), 513-518. doi:10.9788/TP2013.2-16

Camargo, B. V., Justo, A. M., \& Jodelet, D. (2010). Normas, representações sociais e práticas corporais. Interamerican Journal of Psychology, 44(3), 449-457.

Couto, E., \& Meyer, D. (2011). Viver para ser velho? Cuidado de si, envelhecimento e juvenilização. Revista Entreideias: Educação, Cultura e Sociedade, 19, 21-32.

Debert, G. G. (1997). A invenção da terceira idade e a rearticulação de formas de consumo e demandas políticas. Revista Brasileira de Ciências Sociais, 12(34), 39-56.

Diez-Garcia, R. W. (2003). Reflexos da globalização na cultura alimentar: Considerações sobre as mudanças na alimentação urbana. Revista de Nutrição, 16(4), 483-492. doi:10.1590/S141552732003000400011

Editora Abril. (2013). Tabela Circulação Geral. Recuperado em http://www.publiabril.com.br/ tabelasgerais/revistas/circulacao-geral

Freitas, L. (2011). Novos modos de (a) enunciar o masculino na média: $\mathrm{O}$ discurso da publicidade sobre o metrossexual. Revista Litteris, 7, 1-15.

Goetz, E. R. (2013). Beleza e plasticomania. Curitiba, PR: Juruá.

Goetz, E. R., Camargo, B. V., Bertoldo, R. B., \& Justo, A. M. (2008). Representação social do corpo na mídia impressa. Psicologia e Sociedade, 20(2), 226-236. doi:10.1590/S010271822008000200010

Goldenberg, M. (2008). Coroas: Corpo, envelhecimento, casamento e infidelidade. Rio de Janeiro, RJ: Record.
Haboush, A., Warren, C. S., \& Benuto, L. (2011). Beauty, ethnicity, and age: Does internalization of mainstream media ideals influence attitudes towards older adults? Sex Roles, 66(9-10), 668676. doi:10.1007/s11199-011-0102-6

Hubert, A., \& De Labarre, M. (2005). La dictature de la minceur. Cahier de Nutrition et Diététique, 40(6), 300-306. doi:10.1016/S00079960(05)80195-6

Jodelet, D. (1989). Les representationes sociales. Paris: Press Universitaires de France.

Jodelet, D. (2001). Representações sociais: Um domínio em expansão. In D. Jodelet (Ed.), As representações sociais (pp. 17-41). Rio de Janeiro, RJ: Editora da Universidade do Estado do Rio de Janeiro.

Kellner, D. (2001). A cultura da mídia: Estudos culturais: Identidade e politica entre o moderno e o pós-moderno. São Paulo, SP: Editora da Universidade do Sagrado Coração.

Moreira, V., \& Nogueira, F. N. N. (2008). Do indesejável ao inevitável: A experiência vivida do estigma de envelhecer na contemporaneidade. Psicologia USP, 19(1), 59-79. doi:10.1590/ S0103-65642008000100009

Moscovici, S. (1976). La psychanalyse son image et son public. Paris: Presses Universitaires de France.

Moscovici, S. (1981). On social representation. In J. P. Forgas (Ed.), Social cognition (pp. 181-209). London: Academic Press.

Moscovici, S. (2007). Representações sociais: Investigações em psicologia social (5. ed.). Petrópolis, RJ: Vozes.

Palacios, A. D. R. J. (2006). As múltiplas idades e os múltiplos usos: Cultura, consumo e segmentação de público em anúncios de cosméticos. Comunicação, Mídia e Consumo, 3(6).

Preetha, J. P., \& Karthika, K. (2009). Cosmeceuticals - An evolution. International Journal of ChemTech Research, 1(4), 1217-1223.

Reinert, M. (1990). Alceste: une methologie d'analyse dês donnees textualles et une application. Bulletin de Méthodologie Sociologique, 28, 24-54.

Ribeiro, C. J. (2010). Cosmetologia aplicada a dermoestética (2. ed.). São Paulo, SP: Pharmabooks. 
Rizvi, S. I., \& Jha, R. (2010). Current perspectives on anti-aging interventions. Letters in Drug Design \& Discovery, 7(5), 379-388. doi:10.2174/157018010791163488

Sá, C. P. (1996). Núcleo central das representações sociais. Petrópolis, RJ: Vozes.

Santos, G. A. (2002). Os conceitos de saúde e doença na representação social da velhice. Revista Virtual Textos \& Contextos, 1(1), 1-12.

Santos, F. C., \& Damico, J. G. S. (2009). O mal-estar na velhice como construção social. Revista Pensar a Prática, 12(1), 1-9.

Smirnova, M. H. (2012). A will to youth: The woman's anti-aging elixir. Social Science \& Medicine, 75(7), 1236-1243. doi:10.1016/j. socscimed.2012.02.061

Sociedade Brasileira de Cirurgia Plástica. (2014). Minimamente invasivos. Recuperado em http:// www2.cirurgiaplastica.org.br/cirurgias-e-procedimentos/

Teixeira, M. C. T. V., Franchin, A. B. B., Durso, F. A., Donati, L. B., Facin, M. M., \& Pedreschi, P. (2007). Envelhecimento e rejuvenescimento: Um estudo de representação social. Revista Brasileira de Geriatria e Gerontologia, 10(1), 49-71.
Terra, N. L., \& Boschin, R. C. (2004). Mitos e verdades sobre terapias antienvelhecimento. Revista AMRIGS, 48(4), 285-290.

Torres, T. L. (2010). Pensamento social sobre envelhecimento, idoso e rejuvenescimento para diferentes grupos etários (Tese de doutorado em Psicologia, Universidade Federal de Santa Catarina, Florianópolis, SC, Brasil).

Vala, J. (2006). Representações sociais e psicologia social do conhecimento cotidiano. In J. Vala \& B. Monteiro (Eds.), Psicologia social (7. ed., pp. 457-502). Lisboa, Portugal: Fundação Calouste Gulbenkian.

Zani, R. (1994). Beleza e rejuvenescimento: Métodos e técnicas. São Paulo, SP: Saraiva.
Recebido: 06/10/2014

$1^{a}$ revisão: 02/12/2014

$2^{a}$ revisão: 09/01/2015

Aceite final: 14/01/2015 